\title{
Determining Factors That Influence Students' Intention To Adopt Mobile Blackboard: A Case Study At Petra University, Jordan
}

\author{
Fayiz Momani ${ }^{1}$, Omar zghoul ${ }^{1}$, A.K. Hamzah ${ }^{1}$, Waleed Noori Hussein ${ }^{2}$, M.A. \\ Alsalem ${ }^{1}$,Moceheb lazam shuwandy ${ }^{13}$ and Ziadoon.T.Abdulwahhab ${ }^{1}$ \\ ${ }^{1}$ Faculty of Arts, Computing and Creative Industry, Universiti Pendidikan Sultan Idris, \\ Malaysia \\ ${ }^{2}$ Basra University, College of education for pure science, Department of Mathematics \\ ${ }^{3} \mathrm{CCMS}, \mathrm{TU}, \mathrm{IQ}$
}

\begin{abstract}
As a newly developing academic domain, researches on Mobile learning are still in their initial stage. Meanwhile, M-blackboard comes from Mobile learning. This study attempts to discover the factors impacting the intention to adopt mobile blackboard. Eleven selected model on the Mobile learning adoption were comprehensively reviewed. From the reviewed articles, the most factors are identified. Also, from the frequency analysis, the most frequent factors in the Mobile blackboard or Mobile learning adoption studies are performance expectancy, effort expectancy, perceived playfulness, facilitating conditions, self-management, cost and past experiences. The descriptive statistic was performed to gather the respondents' demographic information. It also shows that the respondents agreed on nearly every statement item. Pearson correlation and regression analysis were also conducted.
\end{abstract}

\section{KEYWORDS}

Mobile Learning Adoption, UTAUT, Blackboard, Factors

\section{INTRODUCTION}

Smartphones have given birth to mobile learning as these phones are also usable as tools for accessing online courses. In fact, there has been a dramatic increase in the application of mobile learning. As reported by[1], from 2007 to 2012, there had been an increase in mobile device internet browsing by $300 \%$, denoting an exceptional amount of browsing as opposed to the utilization of desktop in 2012. Smartphones make up 1.08 billion out of the entire 4 billion mobile phones used globally. Based on this, on average, over billion devices that consistently engaged in texting, call logs, banking information and Geographical Positioning System (GPS) location[1]. Then, the last decade of the second millennium saw the emergence of the applications relating to the blackboard as a new trend. The use of blackboard application has been popular among educational institutions in promoting distance learning and in assuring accessibility of study materials to students irrespective of their location and time[2]. As reported by[3], more than $70 \%$ of the colleges and universities in the U.S., used blackboard.

Despite the promising use of the application, it is still unclear with respect to the factors. Those factors have an impact on the intention that used to adopt the mobile-blackboard. There are a number of studies reporting its linkage to the technology and the phone itself. Nonetheless, there are also those reporting its linkage with the users. As for this study, eleven models investigating M-learning adoption will be reviewed. These models were developed in developing country. 


\section{LITERATURE REVIEW}

M-blackboard comprises a form of m-learning and the domain of blackboard has been studied by a number of scholars. Some of the reviewed relevant studies on M-learning are highlighted as below. In institutions of the higher education, the adoption of mobile-learning that has an impact on the factors was highlighted by [4]-[7]. Further, a conceptual model for examining the factors impacting them-learning adoption was introduced. In his work[4], the author includes perceived cost, perceived trust, perceived usefulness, and in addition, the intention of using M-learning in the context of mobile-learning application's for the higher education [8],[9]. Yadav and Sharma [10] employed the diffusion of innovation theory in their examination of the adoption of mobile content services. They empirically reported the significance and influence of the construct of complexity, image, relative advantage, compatibility, cost, observability and voluntariness in the mobile content services adoption.

A literature study conducted by Iqbal and Qureshi [11] was to determine the factors influencing the mobile-learning adoption. In this work, it included perceived playfulness, perceived usefulness, social influence and facilitating conditions. As demonstrated by the findings, three significant factors have an impact on the adoption of mobile learning by the students' intentions. These factors are ease of use, perceived usefulness and facilitating conditions. On the other hand, the construct of perceived playfulness impacts less. Further, the authors reported social influence to negatively impact m-learning adoption. In[12], it explored the factors that have the intended impact of m-learning usage. Perceived ease use, Perceived usefulness, perceived innovativeness, and Perceived ICT anxiety are constructs were used. Based on the data obtained from the completed questionnaire, all factors impact the attitude toward using an intention to use. An empirical study carried out by [13] was to discover factors that impact the adoption of m-learning. Constructs include the Perceived Playfulness, Effort Expectancy, Performance Expectancy, Social Influence, and Self-management of learning have been used. These constructs have been found to be important determinants of behavioral intention to mobile learning usage.

In their study, it used the constructs of Social influence, Effort, and Performance expectancy, Facilitating conditions, Perceived self-efficacy, Perceived credibility, Perceived financial cost[14]. The UTAUT framework was used while those using mobile for m-banking were examined. As found, the intention of the individual that mobile banking adoption was significantly impacted by the factors of perceived financial cost, social influence, and perceived credibility, based on the degree of strength of influence. Facilitating conditions of the individual and the intention have a significant impact on the behavior. Further discussion of the models and their indications. To summarize the extracted factors from the eleven (11) models above, Table 1 presents the factors with highest frequencies.

Table1. Most frequent

\begin{tabular}{|l|l|l|}
\hline No. & Factors & Frequency \\
\hline 1 & Perceived usefulness & 5 \\
\hline 2 & Self-management of leaming & 4 \\
\hline 3 & Perceived ease of use & 4 \\
\hline 4 & Social influence & 3 \\
\hline 5 & Facilitating conditions & 4 \\
\hline 6 & Perceived playfulness & 3 \\
\hline 7 & Cost & 3 \\
\hline 8 & Performance expectancy & 2 \\
\hline 9 & Effort expectancy & 2 \\
\hline 10 & Relative advantage & 2 \\
\hline 11 & Previous experience & 2 \\
\hline
\end{tabular}




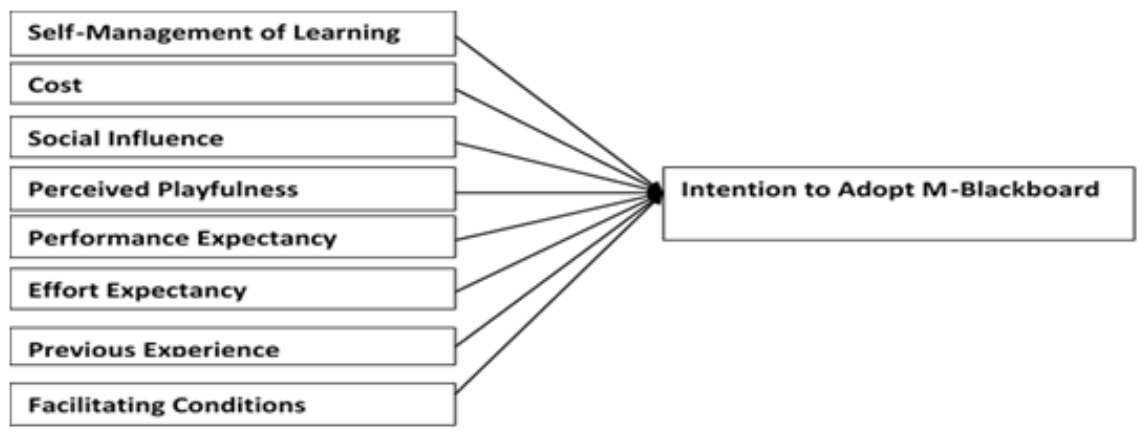

Figure 1. Theoretical research model

Figure 1 shows UTAUT elements that are most widely used constructs. These elements and constructs were studied and used by researchers to explain the M-learning acceptance by students.

\section{ThEORETICAL RESEARCh MOdel}

\subsection{Dependent Variable}

In this study, it is the intention to adopt mobile blackboard by students in Petra University. By reviewing the relating literature for technology adoption in general and to M-Learning in specific, it could be concluded that this dependent variable is might be influenced by many other factors. Therefore, the study assumed that the intention to adopt M-Blackboard is influenced by selfmanagement learning, cost of adoption, social influence of the surrounding environment and people, the degree to which the use of M-Blackboard is perceived enjoyable, the outcome of using the system, the effort that required for using the system, past impression and experience with similar systems, and facilitating condition. Further discussion is given in the following sections.

\subsection{Independent Variables}

It is expected that the intention of M-Blackboard adoption is influenced by the following factors:

\section{a) Self-Management Learning}

According to [15], self-management learning refers to the degree to which a student feels that he is self-disciplined and he can manage his own learning. M-Blackboard requires the students to learn by himself and develop his skills to deploy the blackboard system. In this study, it is expected that self-management learning influence positively the Petra University Students' intention to adopt M-Blackboard[16].

\section{b) Cost}

Cost is one of the most important criteria for making the decision to adopt M-Blackboard or not. In the case of students, who are characterized by limited income, cost constitutes the main indicators of their decision. Most of the studies in the literature that have incorporated the constructed cost have found a negative relationship between cost and adoption of technology [17]. This study is no exception, it is expected that the students' intention to adopt M-Blackboard will be negatively influenced by the cost of adoption. 
Peer review, friend, family, and general environment encourage individual to imitate and adopt technology or in other words "go with the flow" with the current trend. Social influence as defined by [18], is the personal perception that important others believe he should use a new technology. The Model UTAUT incorporated social influence as one of the main constructs and proposed a direct relationship with the intention behavioral of the individual to adopt new technology. In this study, the construct social influence is incorporated and it is expected that the relationship between the intention of mobile-blackboard adoption and the social influence by the student is positive and significant.

\section{d) Perceived Playfulness}

The individual tends to adopt technology that he enjoys with, and benefits from, simultaneously. Perceived playfulness refers to the degree to which individual enjoy while they are learning. Many studies incorporated the construct perceived playfulness and found a direct and positive relationship with the intention behavioral [19]. In this study, the construct perceived playfulness is incorporated and it is expected to have a direct and positive relationship with the intention for Mobile Blackboard adoption by a student at Petra University.

\section{e) Performance Expectancy}

Performance expectancy is one of the most important constructs in UTAUT. The term refers to the degree that the adopters feel that they will benefit from the technology[18]. In [20], [21], it revealed the direct and positive relationship between the mobile learning adoption and the performance expectancy. This study expects that the relationship between the intention to Mobile-Blackboard adoption and the performance expectancy is positive and significant [20] ,[21].

\section{f) Effort Expectancy}

Effort expectancy refers to the degree that the adopter perceives the technology adoption as easy and effortless [18]. Researchers who examined the model UTAUT found a direct and positive relationship between effort expectancy and intention behavioral [4], [20], [22], [23]. This study expects a direct and positive relationship between the intentions of mobile blackboard adoption and effort expectancy by students at Petra University.

\section{g) Previous Experience}

Previous experience constitutes too high degree the perception of current and future decision of adoption. Studies incorporated previous experience found that the previous experience affects positively or negatively the intention to adopt new technology [24]. In [25], it found that previous experience affects the intention to use IT innovation. This study expects that previous experience influence the intention to adopt M-Blackboard by students at Petra University.

\section{h) Facilitating Condition}

Adoption and acceptance of new technology are associated with the supporting condition for the related technology. Facilitating condition is the degree to which individuals believe that there is organizational and infrastructural support for the technology [18] , [26]. Previous literature found a positive relationship between facilitating condition and intention behavioural [22], and with the intention to use M-Learning [11]. This study expects the positive and direct relationship between facilitating condition and intention to adopt M-Blackboard by students at Petra University. 


\subsection{Hypotheses}

H1: A positive relationship between self-management of learning and intention to M-Blackboard system adoption in Petra University in Jordan.

H2: A negative relationship between cost and intention for M-Blackboard system adoption at Petra University in Jordan.

H3: A positive relationship between social influence and intention to adopt M-Blackboard system at Petra University in Jordan

H4: There is a positive relationship between perceived playfulness and intention to adopt MBlackboard system in Petra University in Jordan

H5: There is a positive relationship between performance expectancy and intention to adopt MBlackboard system in Petra University in Jordan.

H7: There is a positive relationship between previous experience and intention to adopt of $\mathrm{M}$ Blackboard system in Petra University in Jordan.

H8: There is a positive relationship between facilitating conditions and the adoption of blackboard system in Petra University in Jordan.

\section{RESEARCH METHODOLOGY}

\subsection{Population and Sampling}

The population selected for this study comprises the entire students that have access to the Blackboard system in the university. According to the university's website (Petra University, 2017), the number of students in the university in 2014 is 6,000. Thus, these 6,000 students become the population of the study. In this study, random selection technique is employed. Here, each student has the chance to be selected as a respondent. According to Sekaran's Table, the sample of this study should comprise 361 respondents.

\section{FINDINGS}

\subsection{Descriptive of the Respondents}

A descriptive statistic presents the demographic information of the respondents. Two hundred and nineteen (219) respondents participated in this study. $92 \%$ of the respondents are in the age group of less than $24.67 .1 \%$ of them were males. A majority (31.5\%) were students in the information technology. A majority of $51.1 \%$ had been using or were aware of the system for a period of 1 and 2 years. More than 93\% possessed Smartphone. Only 19.2\% of the respondents used their Smartphone to access blackboard while $54.8 \%$ used their computer.

\subsection{Reliability}

Table 2 presents the reliability test of the variables of the study. It shows that all the variables have Cronbach's alpha $>0.7$ and that means that all the variables are reliable. 
The International Journal of Multimedia \& Its Applications (IJMA) Vol.9, No.4/5/6, December 2017

Table 2. Reliability analysis

\begin{tabular}{|l|l|l|}
\hline Variables & No. Items & Cronbach's Alpha \\
\hline Facilitating conditions & 4 & 0.768 \\
\hline Perceived Playfulness & 3 & 0.799 \\
\hline Social influence & 3 & 0.800 \\
\hline Cost & 4 & 0.723 \\
\hline Previous Experience & 3 & 0.853 \\
\hline Self-management learning & 3 & 0.849 \\
\hline Performance Expectancy & 3 & 0.783 \\
\hline Effort Expectancy & 4 & 0.758 \\
\hline Intention to Adopt M-Blackboard & 4 & 0.752 \\
\hline
\end{tabular}

\subsection{Regression Analysis and Hypotheses Testing}

Regression analysis was conducted using SPSS version 21.0. The R square of 0.444 indicates that $44 \%$ of the variance in the dependent variable is explainable by the eight independent variables.

Table 3. Model

\begin{tabular}{|l|l|l|l|l|}
\hline \multicolumn{4}{|c|}{ Model Summary } \\
\hline Model & R & R Square & Adjusted R Square & Std. Error of the Estimate \\
\hline 1 & $.666 \mathrm{a}$ & .444 & .423 & 1.14987 \\
\hline a. Predictors: (Constant), Facilitating Condition, Performance Expectancy, \\
Perceived Playfulness, Social Influence, Previous Experience, Cost, Effort \\
Expectancy, Self-Management Learning \\
\hline
\end{tabular}

Table 3 shows $\mathrm{R}$ square $=0.444$ indicates that $44 \%$ of the variance of DV (dependent variables) can be explained by eight IV (independent variables). The percentage of 44 is acceptable. The regression analysis can be used also to determine the most important indicators in explaining the variance in intention to adopt M-Blackboard. Table 4 shows the result of regression analysis.

Table 4. Result of regression analysis

\begin{tabular}{|c|c|c|c|c|}
\hline \multirow{2}{*}{\multicolumn{2}{|c|}{ Model }} & \multicolumn{2}{|c|}{ Unstandardized Coefficients } & \multirow{3}{*}{$\begin{array}{l}\text { Sig. } \\
.000\end{array}$} \\
\hline & & B & Std. Error & \\
\hline \multirow{9}{*}{1} & (Constant) & 5.579 & 1.254 & \\
\hline & Self-Management Learning & .110 & .062 & .000 \\
\hline & Cost & -.097 & .035 & .000 \\
\hline & Perceived Playfulness & .015 & .031 & .634 \\
\hline & Social Influence & .005 & .033 & .887 \\
\hline & Performance Expectancy & .415 & .081 & .000 \\
\hline & Effort Expectancy & .354 & .063 & .000 \\
\hline & Previous Experience & .084 & .062 & .176 \\
\hline & Facilitating Condition & .030 & .047 & .525 \\
\hline
\end{tabular}

Table 4 shows that the strongest indicator is performance expectancy that explained the variance in intention to adopt M-Blackboard $(B=0.415$, p-value $=0.000)$ followed by effort expectancy $(B=0.354$, $p$-value $=0.000)$. Self-management learning and cost are also predicting the variance in the intention to adopt M-Blackboard with $(B=0.110,0.097$ and $\mathrm{p}$-value $=0.000,0.000)$ respectively. Thus, the related hypotheses i.e. $\mathrm{H} 1, \mathrm{H} 2, \mathrm{H} 5, \mathrm{H} 6$ are supported. On the other hand, perceived playfulness, social influence, previous experience, and facilitating condition give no contribution in the explanation of the variance of dependent variable owing to the fact that the $\mathrm{p}$ value for all of them is greater than 0.05 . Thus, $\mathrm{H} 3, \mathrm{H} 4, \mathrm{H} 7, \mathrm{H} 8$ are not supported. 


\section{DISCUSSION}

The regression analysis indicates that four of the hypotheses are accepted and supported while the other four are rejected and not supported. As for the hypothesis 1: There is a positive relationship between self-management of learning and intention for M-Blackboard adoption, it is supported because the p-value is less than 0.05 , which means that self-management learning is a factor that influences the intention to adopt M-Blackboard. This finding supports the previous literature. For instance, [20] looked into the role of self-management learning and deduced that selfmanagement learning influences the m-learning adoption. Likewise, in their study using questionnaire, [19] reported that self-management learning has a positive influence on the English M-Learning adoption[19].

As for hypothesis 2: A negative relationship between cost and the intention for M-Blackboard adoption; it is supported because the p-value is less than 0.05 . Worded differently, the cost is an important factor influencing the intention to adopt M-Blackboard. The less is the cost of acquiring the requirement of M-Blackboard (Smartphone, internet fee, application if any), the higher the possibility of adoption of M-Blackboard, and vice versa. The finding of the study is in agreement with the previous literature. For instance, [17] found in their study that the higher the cost, the less the adoption of the technology will be [17]. In [27], a literature review found cost a significant factor for M-Learning adoption. Likewise, [28] found that cost significantly influences the adoption of mobile device content services.

Hypothesis 3: A positive relationship between social influence and intention for mobile blackboard adoption; this hypothesis is not supported because p-value is greater than 0.05 , which means that social influence is not a key factor impacting the intention M-Blackboard adoption. This result contradicts those of the past works that reported social influence a significant factor that influences the adoption of M-Blackboard and other technology [6], [11], [12], [20], [22]. However, [27] carried out a study to validate the UTAUT model on online community web log system. From the outcomes, the authors concluded that among users with the high or low frequency of using a web log, scores of social influence may not be comparable. As such, the authors mentioned that caution is necessary when interpreting the outcomes from studies that employ the scales of UTAUT. Meanwhile, [11] reported a negative relationship existing between social influence and M-Learning adoption.

With respect to hypothesis 4: There is a positive relationship between perceived playfulness and intention to adopt M-Blackboard; this hypothesis is not supported because the p-value is greater than 0.05 . As such, perceived playfulness is not an effective factor influencing the intention to adopt M-Blackboard. Hence, the finding of the study differs from the finding of others that found significant effects of perceived playfulness [4], [6], [19], [22]. However, [11] in studying MLearning adoption in Pakistan found that perceived playfulness does not influence the adoption of M-Learning and have related that to the service quality of telecommunication companies in Pakistan. This is the only literature that has been found to have a similar result with the result of this study.

As for hypothesis 5: There is a positive relationship between performance expectancy and intention to adopt M-Blackboard; it is supported, as the p-value is less than 0.05 . In other words, performance expectancy significantly affects the intention of M-Blackboard adoption. Therefore, the higher the performance expectancy, the stronger the intention to adopt M-Blackboard by students will be. This finding is in line with those by other researchers. For instance, in investigating the effect of performance expectancy on intention to use M-Learning, [22] found that performance expectancy significantly affects intention to use M-Learning. Likewise, performance expectancy is found to impact students' adoption of M-Learning in the work by [4]. 
Hypothesis 6: A positive relationship between effort expectancy and intention to adopt of $\mathrm{M}$ Blackboard; this hypothesis is supported because the p-value is less than 0.05. In other words, the more effortless the adoption of M-Blackboard, the higher the intention to adopt M-Blackboard will be. The previous literature is in total agreement with the findings of this study. For instance, [20] concluded significance in the relationship between effort expectancy and intention of MLearning usage. In agreement with [20],in [21] reported that effort expectancy significantly influences the adoption mobile device banking.

As for hypothesis 7: A positive relationship between previous experience and intention mobile blackboard adoption; this hypothesis is not supported. This indicates that previous experience has no impact on the intention of M-Blackboard adoption. The finding differs from the previous literature that suggests a strong relationship between previous experience and technology adoption [24], [29]. However, the finding of [25] shows that the relationship between previous experience and intention of MMS technology usage is not significant. In addition, the finding of $[10]$ is in total agreement with the finding of this study.

As for hypothesis 8: A positive relationship between facilitating conditions and blackboard adoption; it is not supported. This indicates that facilitating condition does not influence significantly the intention to adopt M-Blackboard by students in Jordan. This result is in contrast with many results from the previous literature. For instance, the M-Learning acceptance in Korean universities was explored by [29]. Data were gathered using questionnaire. From the results, the authors concluded facilitating condition as a significant factor impacting the adoption and the mobile learning acceptance. Meanwhile, the adoption of mobile learning in developing countries particularly in Pakistan was studied by [11] and the authors concluded that facilitating conditions affect the mobile learning adoption. Additionally, [21] adopted the UTAUT model and conducted a study on the adoption of mobile device banking. The questionnaire was used for data gathering. The findings show the importance of facilitating condition in the adoption of mobile device banking. However, a study conducted by [25] found that facilitating condition does not have any effect on mobile device user's intention to use MMS.

\section{CONCLUSION}

This study comprises a review of eleven models that relate to the adoption of the mobile-learning. The purpose is to find out and identify the factors that effect the adoption of the mobile blackboard. The results show that the most factor that has influence is the performance expectancy with the frequency of nine (9) followed by effort expectancy that has a frequency of six (6). Facilitating condition and self-management learning are frequented by four (4) for each. Social influence, cost, and perceived playfulness are frequented by three (3) for each and finally, previous experience is the least frequent variables. Obviously, there is an intensive usage of UTAUT model by the researchers. The UTAUT constructs are incorporated by researchers to explain the mobile learning adoption or acceptance.

\section{REFERENCES}

[1] Martinez, H. J. (2012). Mobile device security: current challenges and existing solutions (Master of Science thesis). Available from http://scholarworks.wmich.edu/honors_theses/2176.

[2] Almasri, O., Jani, H. M., Ibrahim, Z., \& Zughoul, O. (2013). Improving security measures of elearning database. International Organization of Scientific Research-Journal of Computer Engineering (IOSR-JCE), 10(4), 55-62.

[3] Berry, S. (2017). Building community in online doctoral classrooms: instructor practices that support community. Online Learning, 21(2).

[4] Abu-Al-Aish, A., \& Love, S. (2013). Factors influencing students' acceptance of m-learning: an investigation in higher education. The International Review of Research in Open and Distributed 
The International Journal of Multimedia \& Its Applications (IJMA) Vol.9, No.4/5/6, December 2017

Learning, 14(5).

[5] Alam, S. (2011). Critical success factors of mobile commerce usage in higher learning institution in Malaysia. Australian Journal of Basic and Applied Sciences, 5(12), 2416-2423.

[6] Hussein, W. N., Sulaiman, R., \& Hamzah, A. K. (2013, November). E-business and cloud computing awareness for Malaysian SMEs: A recommendation from academic and industry perspectives. In Research and Innovation in Information Systems (ICRIIS), 2013 International Conference on (pp. 180-185). IEEE.

[7] Zughoul, O., Jani, H. M., Shuib, A., \& Almasri, O. (2013). Privacy and security in online examination systems. International Organization of Scientific Research-Journal of Computer Engineering (IOSRJCE), 10(4), 63-70.

[8] Alaarj, S., Abidin-Mohamed, Z., \& Bustamam, U. S. B. A. (2016). Mediating role of trust on the effects of knowledge management capabilities on organizational performance. Procedia-Social and Behavioral Sciences, 235, 729-738.

[9] Alaarj, S., Mohamed, Z. A., \& Bustamam, U. S. B. A. (2015). The effect of knowledge management capabilities on the performance of Malaysian large-scale organizations: An empirical study. Advances In Global Business Research, 12(1), 1549-9332.

[10] Yadav, R., Sharma, S. K., \& Tarhini, A. (2016). A multi-analytical approach to understand and predict the mobile commerce adoption. Journal of enterprise Information Management, 29(2), 222237.

[11] Iqbal, S., \& Qureshi, I. A. (2012). M-learning adoption: A perspective from a developing country. The International Review of Research in Open and Distributed Learning, 13(3), 147-164.

[12] Seliaman, M. E., \& Al-Turki, M. S. (2012). Mobile learning adoption in Saudi Arabia. World Academy of Science, Engineering and Technology, 69(9), 391-293.

[13] Al-Emran, M., Elsherif, H. M., \& Shaalan, K. (2016). Investigating attitudes towards the use of mobile learning in higher education. Computers in Human Behavior, 56, 93-102.

[14] Alalwan, A. A., Dwivedi, Y. K., \& Rana, N. P. (2017). Factors influencing adoption of mobile banking by Jordanian bank customers: Extending UTAUT2 with trust. International Journal of Information Management, 37(3), 99-110.

[15] Smith, P. J., Murphy, K. L., \& Mahoney, S. E. (2003). Towards identifying factors underlying readiness for online learning: An exploratory study. Distance Education, 24(1), 57-67.

[16] Al Nejam, A., Tang, A. Y., Ahmad, A., \& Ahmad, M. S. (2013). Learning management system using multi-agent technology: a proposed implementation strategy. International Journal of Asian Social Science, 3(9), 1878-1886.

[17] Seyal, A. H., \& Rahim, M. M. (2006). A Preliminary investigation of electronic data interchange adoption in Bruneian small business organizations. The Electronic Journal of Information Systems in Developing Countries, 24.

[18] Venkatesh, V., Morris, M. G., Davis, G. B., \& Davis, F. D. (2003). User acceptance of information technology: Toward a unified view. MIS Quarterly, 425-478.

[19] Huang, R. T., Jang, S. J., Machtmes, K., \& Deggs, D. (2012). Investigating the roles of perceived playfulness, resistance to change and self-management of learning in mobile English learning outcome. British Journal of Educational Technology, 43(6), 1004-1015.

[20] Wang, Y. S., Wu, M. C., \& Wang, H. Y. (2009). Investigating the determinants and age and gender differences in the acceptance of mobile learning. British Journal of Educational Technology, 40(1), 92-118.

[21] Yu, C. S. (2012). Factors affecting individuals to adopt mobile banking: Empirical evidence from the UTAUT model. Journal of Electronic Commerce Research, 13(2), 104.

[22] Hadi, F. Z., \& Kishik, A. A. (2014). Acceptance of mobile learning among university students in Malaysia. Journal of Computing \& Organisational Dynamics, 1-14. 
[23] Jairak, R., Praneetpolgrang, P., \& Mekhabunchakij, K. (2009, December). An investigation of trust in e-learning for instructors and students in private and public universities. In Proc. 6th eLearning for Knowledge-Based Society Conf., Thailand (pp. 17-18).

[24] Jacko, J. A., Barnard, L., Kongnakorn, T., Moloney, K. P., Edwards, P. J., Emery, V. K., \& Sainfort, F. (2004, April). Isolating the effects of visual impairment: exploring the effect of AMD on the utility of multimodal feedback. In Proceedings of the SIGCHI conference on Human factors in computing systems (pp. 311-318). ACM.

[25] Chang, S. E., \& Pan, Y. H. V. (2011). Exploring factors influencing mobile users' intention to adopt multimedia messaging service. Behaviour \& Information Technology, 30(5), 659-672.

[26] Al-Masri, O. H., \& Ahmad, M. S. (2017). A conceptual framework for a problem resolution support system (PReSS). Journal of Advances in Information Technology, 8(2), 148-153.

[27] Liu, Y., Han, S., \& Li, H. (2010). Understanding the factors driving m-learning adoption: a literature review. Campus-Wide Information Systems, 27(4), 210-226.

[28] Gilham, C., \& Van Belle, J. P. (2005). Factors affecting the adoption of mobile content services amongst youth in the Western Cape, South Africa. In Proceedings of the 4th International Business Information Management Conference,(IBIMA), 5-7th July 2005, Lisbon; Portugal (pp. 477-484).

[29] Park, S. Y., Nam, M. W., \& Cha, S. B. (2012). University students' behavioral intention to use mobile learning: Evaluating the technology acceptance model. British Journal of Educational Technology, 43(4), 592-605. 